\title{
Klasterisasi karakteristik kekerasan seksual terhadap anak dengan metode $k$-means cluster analysis
}

\author{
Fana Wiza \\ Program Studi Sistem Informasi Fakultas Ilmu Komputer Universitas Lancang Kuning \\ Jl. Yos Sudarso KM. 8 Rumbai, Pekanbaru, Riau, telp. 08117532015 \\ “e-mail: fana@unilak.ac.id
}

\begin{abstract}
Abstrak
Kekerasan seksual terhadap anak sudah termasuk masalah yang sangat meresahkan di masyarakat khususnya kota Pekanbaru. Semakin banyaknya kasus tindakan kekerasan seksual terhadap anak, maka perlu mencari solusi dan sebuah pengetahuan baru untuk mengatasi permasalahan ini dengan menggali data kasus disertai karakteristik jenis kekerasan, range usia dan faktor pemicu menggunakan algoritma K-Means untuk menghasilkan pola cluster yang terbentuk berdasarkan kedekatan kriteria antar variabel. Teknik yang digunakan dalam aplikasi data mining ini adalah teknik Clustering dengan algoritma K-Means. Algoritma K-Means ini melakukan proses iterasi untuk menghasilkan pola kelompok berdasarkan kedekatan kriteria yang mirip. Teknik ini membantu menganalisis data kasus kekerasan seksual terhadap anak berjumlah 335 data kasus. Melalui data tersebut diperoleh hasil sebanyak 3 cluster. Cluster yang mendominasi adalah cluster 1 dengan kriteria jenis kekerasan seksual pencabulan pada anak di range usia 3 sampai dengan 16 tahun dengan faktor pemicu terbesar adalah kesempatan.
\end{abstract}

Kata kunci : kekerasan, seksual, k-means, clustering, data mining.

\begin{abstract}
Sexual violence against children is one of the most troubling problems in the community, especially in Pekanbaru. The more cases of acts of sexual violence against children, it is necessary to find a solution and a new knowledge to overcome this problem by exploring case data along with the characteristics of violence, age range and trigger factors using the $K$ Means algorithm to produce cluster patterns based on the proximity of criteria variable. The technique used in data mining applications is the Clustering technique with the K-Means algorithm. This K-Means algorithm performs an iterative process to produce group patterns based on similar criteria proximity. This technique helps analyze data on cases of sexual violence against children totaling 335 case data. Through these data, there are 3 clusters of results. The cluster that dominates is cluster 1, with the criteria for the types of sexual abuse sexual abuse for children in the age range of 3 to 16 years with the greatest trigger factor is opportunity.
\end{abstract}

Keywords: violence, sexual, k-means, clustering, data mining.

\section{Pendahuluan}

Dalam Webster's New World's Dictionary tertulis bahwa datum: somethingknown or assumed. Artinya, datum (bentuk tunggal data) merupakan suatu yang diketahui/dianggap. Dengan demikian, data dapat memberi gambaran tentang suatu keadaan atau persoalan [2]. Sedangkan, data menurut kamus Oxford Dictionary adalah The Facts [1]. Jadi, dapat disimpulkan bahwa data adalah sesuatu yang nyata diketahui atau dianggap yang dipakai untuk keperluan suatu analisa, diskusi, presentasi ilmiah atau tes statistic.

Data yang digunakan dalam penelitian ini adalah data kasus kekerasan seksual terhadap anak. Kasus kekerasan seksual terhadap anak yang semakin meningkat cukup membuat masyarakat resah. Kasus kekerasan seksual terhadap anak seperti fenomena gunung es karena 
sebagian besar anak yang menjadi korban enggan melapor. Sebagai orang tua harus dapat memahami jenis kekerasan seksual, usia yang rentan menjadi korban dan pemicu seringnya terjadi kasus kekerasan seksual terhadap anak. Kekerasan seksual terhadap anak akan berdampak pada masalah kesehatan di kemudian hari dan trauma yang berkepanjangan, bahkan hingga dewasa. Dampak trauma akibat kekerasan seksual yang dialami oleh anak-anak, antara lain: pengkhianatan atau hilangnya kepercayaan anak terhadap orang dewasa (betrayal); trauma secara seksual (traumatic sexualization); merasa tidak berdaya (powerlessness); dan stigma (stigmatization). Bila tidak ditangani serius, kekerasan seksual terhadap anak dapat menimbulkan dampak sosial yang luas di masyarakat. Penanganan dan penyembuhan traumapsikis akibat kekerasan seksual haruslah mendapat perhatian besar dari semua pihak yang terkait, seperti keluarga, masyarakat maupun negara. Oleh karena itu, didalam memberikan perlindungan terhadap anak perlu adanya pendekatan sistem, yang meliputi sistem kesejahteraan sosial bagi anak-anak dan keluarga,sistem peradilan yang sesuai dengan standar internasional, dan mekanisme untuk mendorong perilaku yang tepat dalam masyarakat. Untuk mengenali bentuk-bentuk kekerasan terhadap anak sesungguhnya tidaklah jauh dari sekitar kita. Realitas kekerasan yang dialami anak-anak sampai saat ini masih menjadi masalah yang cukup besar di Indonesia. Pemberitaan media cetak dan elektronik mengenai kekerasan seksual pada anak dapat dijumpai setiap hari. Bentuk dan modus operasinya pun juga cukup beragam. Berdasarkan ketentuan Konvensi Hak Anak (1989) dan protokol tambahannya KHA (option protocol Convention on the Rights of the Child) bentuk-bentuk kekerasan dibagi dalam empat bentuk. Kekerasan seksual meliputi eksploitasi seksual komersial. Kekerasan seksual terhadap atau dengan sebutan lain perlakuan salah secara seksual. Bentuk lainnya adalah pencabulan dan incest [3]. Data mining do discovering interesting patterns from amounts of data. It is a young interdisciplinary field, from areas such as database systems, statistics, artificial intelligent, information retrieval. Other contributing areas as neural networks, pattern recognition, spatial data analysis, image databases, signal processing, and many application fields, such as business, economics, and bioinformatics [4].

Data mining merupakan analisis dari sekumpulan data yang diamati (sangat besar) untuk menemukan hubungan yang tidak terduga dan merangkum data dengan cara yang baru yang dapat dipahami dan berguna bagi pemilik data [5]. Data mining menganalisis data menggunakan tool untuk menemukan pola dan aturan dalam himpunan data. Perangkat lunak bertugas untuk menemukan pola dengan mengidentifikasi aturan dan fitur pada data. Tool data mining diharapkan mampu mengenal pola ini dalam data dengan input minimal dari user [6].

Data mining dapat menjalankan fungsi-fungsi berikut:

1. Deskripsi

Pola dan trend data sering dideskripsikan. Deskripsi tersebut sangat membantu dalam menjelaskan pola dan trend yang terjadi. Model data mining harus setransparan mungkin, dimana hasilnya dapat mendeskripsikan pola dengan jelas.

2. Estimasi

Estimasi mirip dengan klasifikasi kecuali variabel target-nya numerik ketimbang kategorikal. Model yang dibangun menggunakan record yang lengkap, yang menyediakan nilai variabel target dan predictor. Untuk observasi yang baru, estimasi nilai variabel target ditentukan, berdasarkan nilai-nilai predictor.

3. Prediksi

Prediksi mirip dengan klasifikasi dan estimasi, kecuali dalam prediksi, hasil terjadi di masa datang.

4. Klasifikasi

Dalam klasifikasi, variabel target-nya merupakan kategorikal. Model data mining memeriksa setrecord yang besar, tiap record mempunyai informasi variabel target dan set input atau variabel predictor.

5. Clustering

Clustering merupakan pengelompokkan record, observasi, atau kasus ke dalam kelas-kelas objek yang mirip. Clustering berbeda dengan klasifikasi dimana dalam 
clustering tidak terdapat variabel target. Clustering mencoba menyegmentasi seluruh set data ke dalam subgroup atau cluster yang relatif homogen, dimana kemiripan antar record dalam cluster dimaksimalisasi dan kemiripan record di luar cluster diminimalisasi.

6. Asosiasi

Asosiasi merupakan suatu tugas untuk menemukan atribut-atribut yang terjadi bersamaan. Tugas asosiasi mencoba untuk menemukan aturan untuk mengkuantifikasi hubungan antara dua atau lebih atribut. Aturan asosiasi berbentuk "If antecedent, then consequent", bersama-sama dengan ukuran support dan confidence yang berhubungan dengan aturan [7].

Data mining merupakan upaya untuk menggali informasi dan pengetahuan yang berharga pada database yang besar. Pada penelitian ini akan dilihat pola cluster kasus kekerasan seksual terhadap anak berdasarkan kedekatan dengan range usia korban dan pemicu. Pola hubungan dua variabel atau lebih dapat tergambar dalam cluster yang terbentuk dengan hubungan sebab akibat ataupun secara kebetulan. Dalam hal ini, pola cluster hubungan yang dimaksud adalah hasil dari data mining dengan algortima k-means clustering.

Berdasarkan latar belakang di atas, maka rumusan masalah penelitian ini adalah dengan data mining, bagaimana mengolah tumpukan data dan menghasilkan informasi yang baru sehingga dapat dilihat informasi pola kekerasan seksual terhadap anak dalam bentuk cluster berdasarkan kedekatan karakteristik menggunakan algoritma k-means?

Manfaat yang diperoleh dari hasil penelitian ini adalah menjadi tolak ukur pihak Polresta Pekanbaru dalam menganalisis pola kelompok tindak kekerasan seksual terhadap anak yang terjadi berdasarkan kedekatan karakteristik range usia dan pemicu. Informasi yang diperoleh dapat dianalisa lebih lanjut untuk membuat penanganan yang tepat mengenai keputusan tentang tindak kekerasan, menekan jumlah tindak kekerasan, serta dapat bersosialisasi langsung terhadap masyarakat. Memberikan kesadaran kepada masyarakat, khususnya bagi para orang tua untuk mencegah atau untuk menghadapi kasus kekerasan seksual terhadap anak.

\section{Metode Penelitian}

Sebagai langkah awal maka perlu adanya studi literatur untuk menentukan metode data mining yang manakah untuk mengekstrak data dan algoritma yang tepat dalam penentuan alternatif solusi. Selanjutnya identifikasi masalah berkenaan dengan masalah yang di bahas, kemudian dilakukan pengumpulan data berkaitan dengan permasalahan yang akan dibahas, kemudian dilakukan pengumpulan data untuk menentukan parameter-parameter yang akan dijadikan landasan dalam penelitian.

Penelitian ini melakukan mining pada data kasus kekerasan terhadap anak di Polresta Pekanbaru dari tahun 2014 sampai dengan tahun 2017. Data tersebut masuk ke langkah pertama yaitu pra proses. Pra proses pertama yaitu data cleaning. Data yang memiliki atribut tidak lengkap atau kosong akan di eliminasi. Selanjutnya pra proses data integration, data yang berjenis data nominal diinisialisasi ke bentuk number supaya bisa diolah oleh algoritma $K$ means. Data integration dilakukan sejalan dengan pra proses task relevan data yaitu seleksi atribut yang relevan dengan rumusan masalah peneliti.

K-Means adalah metode klaster data non-hirarkis yang mencoba untuk membagi data ke dalam satu atau lebih klaster. Jarak paling dekat antara satu data dengan satu cluster tertentu akan menentukan suatu data masuk dalam cluster mana. Untuk menghitung jarak semua data ke setiap tiitk pusat cluster dapat menggunakan teori jarak Euclidean [8]. Metode ini membagi data ke klaster yang memiliki karakteristik serupa berkumpul di cluster yang sama. K-Means juga disebut sebagai algoritma klaster berulang [9].

Two main approaches are clustering with partition approach, and hierarchical approach. Clustering with partition approach is often referred to as partition or partition-based clustering to group the data by sifting through the data analyzed in the existing clusters. Clustering with the hierarchical approach is often called clustering hierarchical group data by creating a 
hierarchy in the form of a dendogram, in which data will be placed on a hierarchy similar to the adjacent and which are not that far apart on the hierarchy [10].

Algoritma K-Means dimulai dengan pilihan acak, dimana $k$ adalah jumlah cluster yang akan dibentuk. Kemudian mengatur nilai-nilai $k$ acak, untuk sementara bahwa nilai-nilai akan menjadi pusat cluster atau biasa disebut centroid. Hitung jarak setiap data ke masing-masing centroid menggunakan rumus Euclidean untuk mencari jarak terdekat dari masing-masing data dengan centroid. Kemudian mengklasifikasikan setiap data berdasarkan dekat dengan pusat massa. Titik migrasi data akan selalu terjadi sampai massa tidak berubah lagi atau stabil [11].

Langkah-langkah melakukan clustering dengan metode $\mathrm{K}$-Means adalah sebagai berikut:

1. Pilih jumlah cluster $k$.

2. Inisialisasi $k$ pusat cluster ini bisa dilakukan dengan berbagai cara. Namun yang paling sering dilakukan adalah dengan cara random. Pusat-pusat cluster diberi nilai awal dengan angka-angka random,

3. Alokasikan semua data/objek ke cluster terdekat. Kedekatan dua objek ditentukan berdasarkan jarak kedua objek tersebut. Demikian juga kedekatan suatu data ke cluster tertentu ditentukan jarak antara data dengan pusat cluster. Dalam tahap ini perlu dihitung jarak tiap data ke tiap pusat cluster. Jarak paling antara satu data dengan satu cluster tertentu akan menentukan suatu data masuk dalam cluster

$$
\begin{aligned}
& D(i, j)=\sqrt{\left(X_{1 i}-X_{1 j}\right)^{2}+\left(X_{2 i}-X_{2 j}\right)^{2}+\cdots+\left(X_{k i}-X_{k j}\right)^{2}} \ldots \text { (1) } \\
& \text { dimana: } \\
& D(i, j)=\text { Jarak data ke } i \text { ke pusat cluster } j \\
& X_{k i}=\text { Data ke } i \text { pada atribut data ke } k \\
& X_{k j}=\text { Titik pusat ke } j \text { pada atribut ke } k
\end{aligned}
$$

mana. Untuk menghitung jarak semua data ke setiap tiitk pusat cluster dapat menggunakan teori jarak Euclidean yang dirumuskan sebagai berikut:

4. Hitung kembali pusat cluster dengan keanggotaan cluster yang sekarang. Pusat cluster adalah rata-rata dari semua data/objek dalam cluster tertentu. Jika dikehendaki bisa juga menggunakan median dari cluster tersebut. Jadi rata-rata (mean) bukan satu-satunya ukuran yang bisa dipakai.

5. Tugaskan lagi setiap objek memakai pusat cluster yang baru. Jika pusat cluster tidak berubah lagi maka proses clustering selesai. Atau, kembali ke langkah nomor 3 sampai pusat cluster tidak berubah lagi.

Data yang digunakan dalam penelitian ini adalah khusus data kasus kekerasan terhadap anak dengan jenis kekerasan seksual. Jenis kekerasan seksual yang terdata di Polresta Pekanbaru adalah jenis kekerasan seksual cabul, eksploitasi, dan penganiayaan seksual. Data kasus kekerasan seksual terhadap anak ini akan diklaster berdasarkan kedekatan karakteristik range usia korban dan pemicu. Atribut yang digunakan adalah nomor kasus, jenis kekerasan, range usia korban, dan pemicu. Nomor kasus adalah pengganti nama korban karena nama korban tidak boleh dipublikasikan. Semua data yang telah didapatkan tadi kemudian diolah dengan data mining menggunakan algoritma $K$-Means Clustering.

Hasil proses ini adalah data yang dikelompokkan berdasar kemiripan karakteristik dari setiap data, sehingga dapat ditemukan pola atau informasi yang tersembunyi dari data-data tersebut. Selanjutnya dilakukan knowledge presentation yaitu formulasi keputusan atau aksi dari hasil yang didapat. Formula yang dihasilkan adalah output penelitian ini. Output tersebut akan menjawab masalah yang telah dirumuskan di awal. 


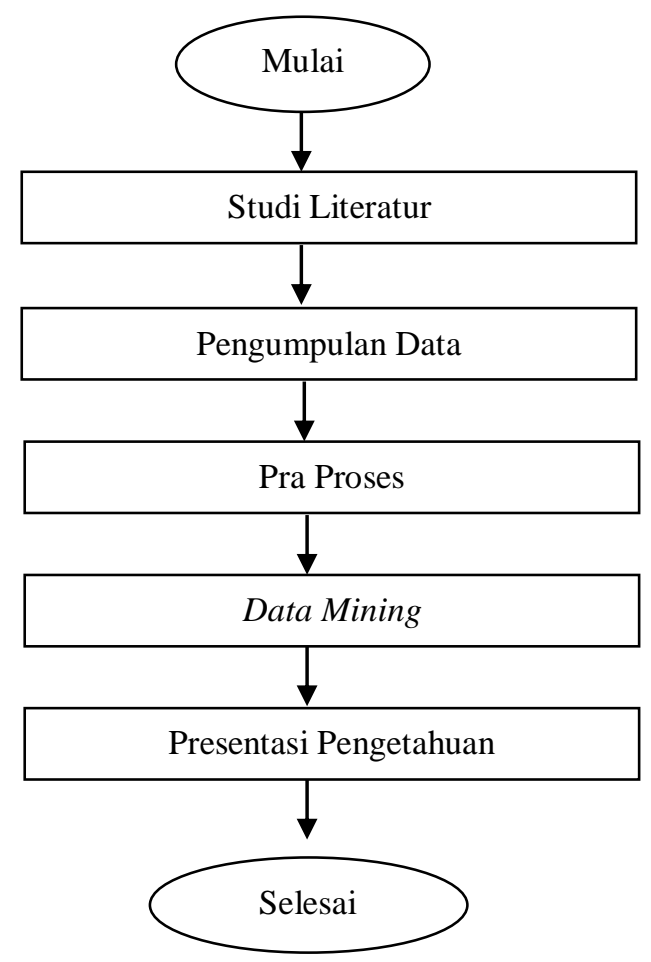

Gambar 1. Bagan Alir Kerangka Kerja Penelitian

\section{Hasil dan Pembahasan}

\subsection{Pra Proses}

Tahap pra proses ini meliputi pembersihan data (data cleaning), integrasi data (data integration), task relevant data. Data-data yang tidak lengkap isinya tidak dilibatkan dalam penelitian. Dan data-data yang lengkap isinya, dipilih beberapa atribut agar benar-benar relevan dengan kebutuhan penelitian demi meningkatkan performa dalam proses mining.

Task relevant data membantu tahapan proses data mining dalam menemukan pola data yang berguna. Oleh karena itu, tidak semua atribut data akan digunakan, hanya atribut yang dianggap peneliti berguna dan sebarannya tidak terlalu acak.

Tabel 1. Atribut yang digunakan

\begin{tabular}{|l|l|}
\hline \multicolumn{1}{|c|}{ Aribut } & \multicolumn{1}{c|}{ Keterangan } \\
\hline Jenis Kekerasan & $\begin{array}{l}\text { Jenis kekerasan merupakan suatu tindakan } \\
\text { atau bentuk perlakuan yang dapat } \\
\text { merugikan korban secara fisik maupun } \\
\text { secara psikologis. }\end{array}$ \\
\hline Usia & $\begin{array}{l}\text { Usia merupakan jarak atau range usia } \\
\text { terhadap seseorang. }\end{array}$ \\
\hline $\begin{array}{l}\text { Faktor atau } \\
\text { Pemicu }\end{array}$ & $\begin{array}{l}\text { Faktor atau Pemicu merupakan suatu } \\
\text { keadaan yang dapat terjadi secara ketidak } \\
\text { sengajaan atau juga kesengajaan yang } \\
\text { sudah direncanakan. }\end{array}$ \\
\hline
\end{tabular}

Seringkali data yang akan digunakan dalam proses data mining mempunyai format yang belum langsung bisa digunakan. Oleh karena itu, formatnya perlu dirubah Dalam penelitian ini data yang berjenis data nominal diinisialisasikan ke dalam bentuk angka agar dapat diolah dengan menggunakan algoritma K-means Clustering. Tahap ini sejalan dengan proses task relevan data. Parameter yang digunakan adalah sebagai berikut : 
Tabel 2. Hasil Inisialilasi Data

\begin{tabular}{|l|l|}
\hline \multicolumn{2}{|l|}{ Jenis Kekerasan } \\
\hline 1 & $\begin{array}{l}\text { Cabul merupakan tindakan yang melanggar kesopanan } \\
\text { atau perbuatan yang melanggar asusila. }\end{array}$ \\
\hline 2 & $\begin{array}{l}\text { Penganiayaan seksual anak merupakan bentuk tindakan } \\
\text { kekerasan secara seksual. }\end{array}$ \\
\hline 3 & $\begin{array}{l}\text { Eksploitasi anak merupakan bentuk paksaan dan } \\
\text { kekerasan terhadap anak untuk dijadikan perbudakan dan } \\
\text { paksaan dalam hal seksual. }\end{array}$ \\
\hline Range Usia \\
\hline 1 & Range usia 3 - 16 tahun \\
\hline 2 & Range usia 9 - 18 tahun \\
\hline 3 & Range Usia 12 - 16 tahun \\
\hline 4 & Range Usia 6 - 9 tahun \\
\hline 5 & Range Usia 14 - 18 tahun \\
\hline 6 & Range Usia 9 -15 tahun \\
\hline Pemicu & $\begin{array}{l}\text { Niat merupakan tindakan yang sudah direncanakan } \\
\text { sebelumnya. }\end{array}$ \\
\hline 2 & $\begin{array}{l}\text { Kesempatan merupakan adanya suatu keadaan yang } \\
\text { mengundang orang untuk melakukan kejahatan walaupun } \\
\text { tidak terencana sebelumnya. }\end{array}$ \\
\hline 3 & $\begin{array}{l}\text { Emosi merupakan perasaan/reaksi terhadap seseorang } \\
\text { yang dilakukan secara intens. }\end{array}$ \\
\hline 4 & $\begin{array}{l}\text { Ekonomi merupakan faktor sosial yang dapat memicu } \\
\text { terjadinya kekerasan dengan tidak terpenuhinya } \\
\text { kebutuhan sehari - hari. }\end{array}$ \\
\hline 5 & $\begin{array}{l}\text { Ketidak Sengajaan merupakan tindakan } \\
\text { pengabaian/kurangnya pengawasan terhadap anak yang } \\
\text { dapat menyebabkan terjadinya kejadian yang tidak } \\
\text { diduga. }\end{array}$ \\
\hline 6 & $\begin{array}{l}\text { Pacaran merupakan proses perkenalan antara dua insan } \\
\text { manusia yang mencari kecocokan untuk menuju ketahap } \\
\text { berkeluarga atau yang dikenal dengan pernikahan. }\end{array}$ \\
\hline 7 & $\begin{array}{l}\text { Asmara merupakan perasaan penasaran kepada lawan } \\
\text { jenis yang dapat menimbulkan rasa cinta. }\end{array}$ \\
\hline 8 & $\begin{array}{l}\text { Perceraian merupakan putusnya suatu perkawinan secara } \\
\text { agama dan diputuskan di depan hakim yang telah diatur } \\
\text { oleh Undang-Undang. }\end{array}$ \\
\hline 9 & $\begin{array}{l}\text { Pengabaian Orang Tua merupakan tindakan tidak adanya } \\
\text { perhatian yang diberikan orang tua terhadap anaknya. }\end{array}$ \\
\hline
\end{tabular}

\subsection{Proses Data Mining dengan Algoritma K-means Clustering}

Dengan ini, maka hasil analisa 3 variabel, yaitu status korban, jenis kekerasan, dan faktor penyebab, diperoleh informasi dengan pengujian 307 data kasus kekerasan dalam rumah tangga yang dilakukan dengan menggunakan software weka 3.5.5 telah didapatkan informasi bahwa jika didalam suatu rumah tangga itu terjadi tindak kekerasan dalam rumah tangga, korbannya- adalah seorang ibu rumah tangga atau isteri dengan kekerasan yang dialaminyaadalah kekerasan fisik yang disebabkan oleh faktor ekonomi. 
Pada tahap proses mining peneliti menggunakan tools aplikasi Tanagra 1.4.50. Langkah awal adalah mempersiapkan dataset dalam format yang support oleh aplikasi tersebut seperti berikut.

Tabel 3. Dataset

\begin{tabular}{|c|c|c|c|}
\hline No & $\mathbf{X i}$ & $\mathbf{Y i}$ & $\mathbf{Z i}$ \\
\hline 1 & 1 & 1 & 1 \\
\hline 2 & 1 & 1 & 1 \\
\hline 3 & 1 & 1 & 1 \\
\hline 4 & 1 & 1 & 2 \\
\hline 5 & 1 & 1 & 1 \\
\hline 6 & 1 & 1 & 2 \\
\hline 7 & 1 & 1 & 1 \\
\hline 8 & 1 & 1 & 2 \\
\hline 9 & 1 & 1 & 2 \\
\hline 10 & 1 & 1 & 2 \\
\hline$\ldots$ & $\ldots$ & $\ldots$ & $\ldots$ \\
\hline 335 & 2 & 2 & 3 \\
\hline
\end{tabular}

Kemudian import dataset dalam aplikasi. Setelah proses import selesai. Aplikasi meksekusi status file dataset yang diimport dengan hasil sebagai berikut :

Tabel 4. Download Information

\section{Workbook information}

Number of sheets

Selected sheet

Sheet size

Dataset size
3

\section{Sheet1}

$316 \times 4$

$316 \times 4$

\section{Datasource processing}

Computation time

$62 \mathrm{~ms}$

Allocated memory

$16 \mathrm{~KB}$

\section{Dataset Description}

4 attribute(s)

315 example(s)

\begin{tabular}{|c|c|c|}
\hline Attribute & Category & Informations \\
\hline No & Continue & - \\
\hline $\mathrm{Xi}$ & Continue & - \\
\hline$Y i$ & Continue & - \\
\hline $\mathrm{Zi}$ & Continue & - \\
\hline
\end{tabular}

Selanjutnya melakukan input paramater yang digunakan sesuai atribut yang sudah kita pilih sebelumnya. Seperti berikut ini : 
Tabel 6. Tampilan Informasi Atribut di Aplikasi

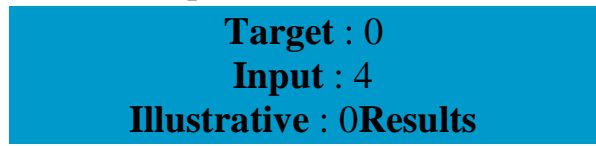

\begin{tabular}{|l|l|l|l|}
\hline Attribute & Target & Input & Illustrative \\
\hline $\mathrm{No}$ & - & yes & - \\
\hline $\mathrm{Xi}$ & - & yes & - \\
\hline $\mathrm{Yi}$ & - & yes & - \\
\hline $\mathrm{Zi}$ & - & yes & - \\
\hline
\end{tabular}

Hasil pengolahan dengan algoritma K-Means :

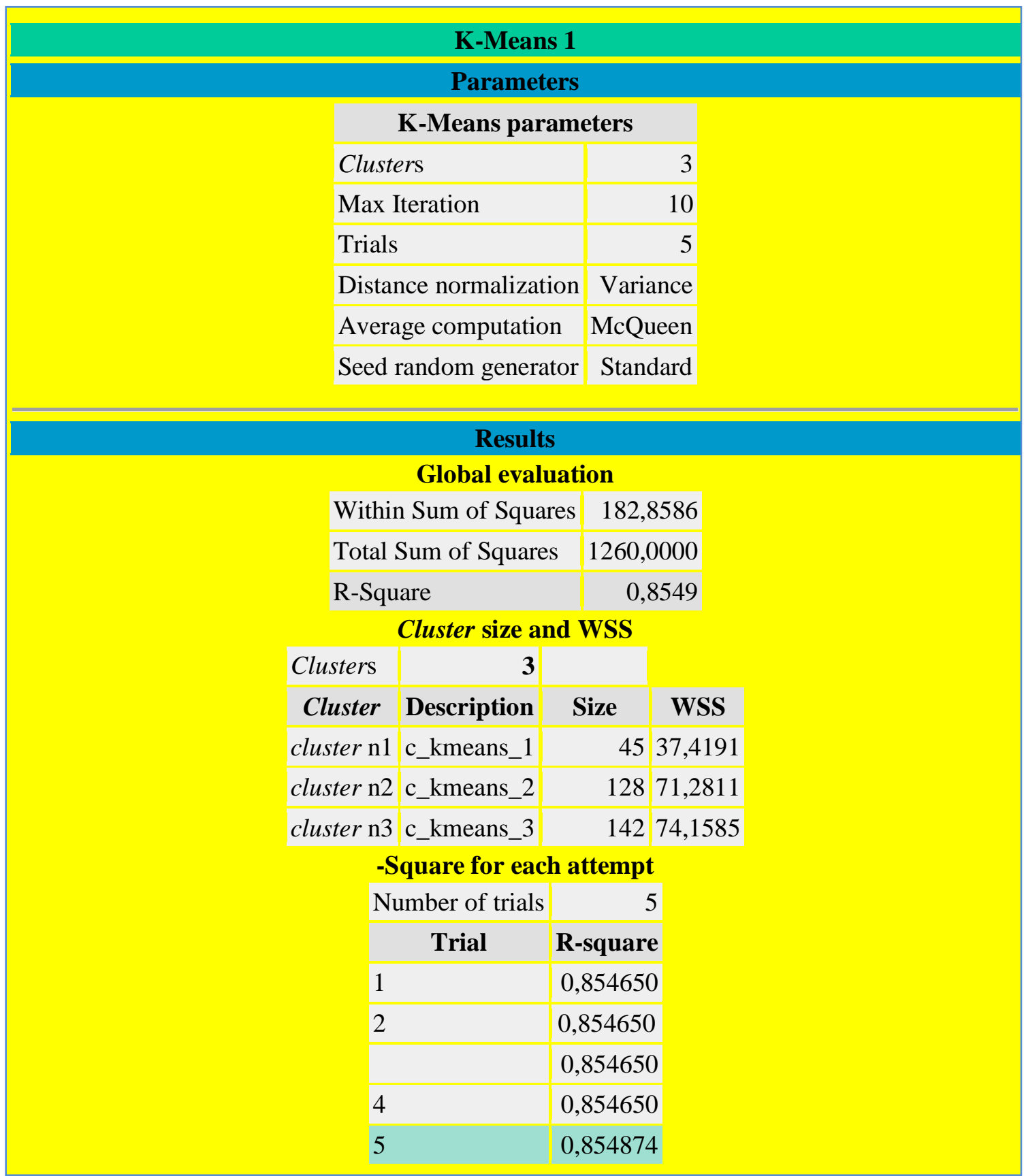


Tabel 7. Cluster centroids

\begin{tabular}{|l|r|r|r|}
\hline Attribute & Cluster n1 & Cluster n2 & Cluster n3 \\
\hline No & 257,044444 & 243,703125 & 72,345070 \\
\hline $\mathrm{Xi}$ & 2,000000 & 1,000000 & 1,000000 \\
\hline $\mathrm{Yi}$ & 2,000000 & 1,000000 & 1,000000 \\
\hline $\mathrm{Zi}$ & 3,444444 & 1,445313 & 1,570423 \\
\hline
\end{tabular}

Cluster yang dihasilkan :

1. Cluster 1

Klaster 1 terdiri dari kasus kekerasan seksual sejumlah 142 kasus atau dapat dikatakan 42\%dari seluruh kasus. Seluruh kasus dalam cluster ini adalah kasus kekerasan seksual pencabulan pada anak di range usia 3 sampai dengan 16 tahun. Kriteria faktor pemicu yang mendominasi adalah kesempatan dengan persentasi $57 \%$ dan niat sejumlah $43 \%$.

2. Cluster 2

Klaster 2 terdiri dari kasus kekerasan seksual sejumlah 128 kasus atau dapat dikatakan $38 \%$ dari seluruh kasus. Seluruh kasus dalam cluster ini adalah kasus kekerasan seksual pencabulan pada anak di range usia 3 sampai dengan 16 tahun. Kriteria faktor pemicu yang mendominasi adalah niat dengan persentasi 55,5\% dan kesempatan sejumlah $44,5 \%$.

3. Cluster 3

Klaster 3 terdiri dari kasus kekerasan seksual sejumlah 45 kasus atau dapat dikatakan $13 \%$ dari seluruh kasus. Kasus dalam cluster ini adalah kasus kekerasan seksual penganiayaan seksual pada anak di range usia 9 sampai dengan 18 tahun. Kriteria faktor pemicu yang mendominasi adalah faktor emosi dengan persentasi 55,5\% dan faktor ekonomi sejumlah $44,5 \%$.

\section{Kesimpulan}

Setelah dilakukan clustering data kasus kekerasan seksual pada anak pada data Polresta Pekanbaru tahun 2014 sampai dengan tahun 2017 berdasarkan kriteria jenis kekerasan, range usia dan faktor pemicu menggunakan algoritma K-Means terbentuk tiga cluster. Cluster yang terbentuk berupa formula yang dapat dijadikan tolak ukur oleh pihak Polresta Pekanbaru dalam menganalisis pola kelompok tindak kekerasan seksual terhadap anak yang paling dominan terjadi disertai kriteria yang mendominasi yaitu jenis kekerasan, range usia dan faktor pemicu. Informasi yang diperoleh dapat dianalisa lebih lanjut untuk sebagai bahan pertimbangan dalam pengambilan keputusan untuk penanganan yang tepat terhadap tindak kekerasan, menekan jumlah tindak kekerasan, dapat bersosialisasi langsung terhadap masyarakat dan memberikan kesadaran kepada masyarakat, khususnya bagi para orang tua untuk mencegah dan menghadapi tindak kekerasan seksual terhadap anak.

\section{Daftar Pustaka}

[1] Ong, Johan Oscar. "Implementasi Algoritma K-Means Clustering Untuk Menentukan Strategi Marketing President University." (2013).

[2] Setiawan, Rony. "Penerapan Data Mining Menggunakan Algoritma K-means Clustering Untuk Menentukan Strategi Promosi Mahasiswa Baru (Studi Kasus: Politeknik LP3I Jakarta)." Jurnal Lentera Ict 3.1 (2017): 76-92.

[3] Kusumawati, Aditya, Zahroh Shaluhiyah, and Antono Suryoputro. "Tradisi Kekerasan Seksual sebagai Simbol Kekuasaan pada Anak Jalanan di Kota Semarang." The Indonesian Journal of Health Promotion (Jurnal Promosi Kesehatan Indonesia) 9.1

[4] Han, Jiawei, Micheline Kamber, and Data Mining. "Concepts and techniques." Morgan Kaufmann 340 (2006): 94104-3205. 
[5] Pratikto, F. Rian, and T. Gerry. "Penerapan Data Mining Dalam Penentuan Aturan Asosiasi Antar Jenis Item." Jurnal Fakultas Hukum UII.

[6] Sulianta, Feri, and Dominikus Juju. Data Mining. Elex Media Komputindo, 2010.

[7] Tampubolon, Kennedi, et al. "Implementasi Data Mining Algoritma Apriori pada sistem persediaan alat-alat kesehatan." Informasi dan Teknologi Ilmiah (INTI) 1.1 (2013): 93106.

[8] Asril, Elvira, Fana Wiza, and Yogi Yunefri. "Analisis Data Lulusan dengan Data Mining untuk Mendukung Strategi Promosi Universitas Lancang Kuning." Digital Zone: Jurnal Teknologi Informasi dan Komunikasi 6.2 (2015): 24-32.

[9] Ningrat, Desy Rahmawati, I. Maruddani Di Asih, and Triastuti Wuryandari. "Analisis Cluster dengan Algoritma K-Means dan Fuzzy C-Means Clustering untuk Pengelompokan Data Obligasi Korporasi." Jurnal Gaussian 5.4 (2016): 641-650.

[10] GPA, AT DATA STUDENT BASED ON. "Analysis and implementation of algorithm clustering affinity propagation and k-means at data student based on GPA and duration of bachelor-thesis completion." Journal of Theoretical and Applied Information Technology 35.1 (2012).

[11] Kom, Darsono M. "PENGGUNAAN ALGORITMA CLASIFICATION AND REGRESSION TREE (CART) UNTUK MENDUKUNG KEPUTUSAN PADA PENILAIAN SERTIFIKASI GURU." Nusantara of Engineering 1.1 (2014). (2016): 1731. 